\title{
1 Microbial cysteine degradation is a source of hydrogen 2 sulfide in oxic freshwater lakes
}

4 Patricia Q. Tran ${ }^{1,2 *}$, Samantha C. Bachand ${ }^{1 *}$, Jacob C. Hotvedt $^{1 *}$, Kristopher Kieft $^{1,3}$, Elizabeth 5 A. McDaniel ${ }^{1,3}$, Katherine D. McMahon ${ }^{1,4}$, Karthik Anantharaman ${ }^{1+}$

1. Department of Bacteriology, University of Wisconsin-Madison, WI, USA

2. Department of Integrative Biology, University of Wisconsin-Madison, WI, USA

4. Department of Civil and Environmental Engineering, University of Wisconsin-Madison, WI, USA

$14 *$ Patricia Q. Tran, Samantha C. Bachand and Jacob C. Hotvedt are co-first authors.

16 + Corresponding author: Karthik Anantharaman (karthik@bact.wisc.edu) 


\section{Abstract}

24 The sulfur-containing amino acid cysteine is abundant in the environment including in

25 freshwater lakes. Biological degradation of cysteine can result in hydrogen sulfide $\left(\mathrm{H}_{2} \mathrm{~S}\right)$, a toxic and ecologically relevant compound that is a central player in biogeochemical cycling in aquatic environments, including freshwater lakes. Here, we investigated the ecological significance of cysteine in oxic freshwater lake environments, using model systems of isolated cultures, controlled growth experiments, and multi-omics. We screened bacterial isolates enriched from natural lake water for their ability to produce $\mathrm{H}_{2} \mathrm{~S}$ when provided cysteine. In total, we identified 29 isolates that produced $\mathrm{H}_{2} \mathrm{~S}$ and belonged to the phylum proteobacteria Bacteroidetes, Proteobacteria and Actinobacteria. To understand the genomic and genetic basis for cysteine degradation and $\mathrm{H}_{2} \mathrm{~S}$ production, we further characterized 3 freshwater isolates using wholegenome sequencing, and quantitatively tracked cysteine and $\mathrm{H}_{2} \mathrm{~S}$ levels over their growth ranges: Stenotrophomonas maltophila, Stenotrophomonas bentonitica (Gammaproteobacteria) and Chryseobacterium piscium (Bacteroidetes). We observed a decrease in cysteine and increase in $\mathrm{H}_{2} \mathrm{~S}$, and identified genes involved in cysteine degradation in all 3 genomes. Finally, to assess the presence of these organisms and genes in the environment, we surveyed a five-year time series of metagenomic data from the same isolation source at Lake Mendota and identified their presence throughout the time series. Overall, our study shows that sulfur-containing amino acids can drive microbial $\mathrm{H}_{2} \mathrm{~S}$ production in oxic environments. Future considerations of sulfur cycling and biogeochemistry in oxic environments should account for $\mathrm{H}_{2} \mathrm{~S}$ production from degradation of organosulfur compounds.

\section{Importance}

46 Hydrogen sulfide $\left(\mathrm{H}_{2} \mathrm{~S}\right)$, a naturally occurring gas with biological origins, can be toxic to living

47 organisms. In aquatic environments, $\mathrm{H}_{2} \mathrm{~S}$ production typically originates from anoxic (lacking oxygen) environments such as sediments, or the bottom layers of lakes. However, the

49 degradation of sulfur-containing amino acids such as cysteine, which all cells and life forms rely

50 on, can be a source of ammonia and $\mathrm{H}_{2} \mathrm{~S}$ in the environment. Unlike other approaches for the

51 biological production of $\mathrm{H}_{2} \mathrm{~S}$ such as dissimilatory sulfate reduction, cysteine degradation can 
occur in the presence of oxygen. Yet, little is known about how cysteine degradation influences sulfur availability and cycling in freshwater lakes. In our study, we found that multiple bacteria originating from a freshwater lake can not only produce $\mathrm{H}_{2} \mathrm{~S}$, but do so in oxic conditions. Overall, our study highlights the ecological importance of oxic $\mathrm{H}_{2} \mathrm{~S}$ production in natural ecosystems, and necessitates a change in our outlook of sulfur biogeochemistry.

\section{Introduction}

In most natural environments, the production of hydrogen sulfide gas $\left(\mathrm{H}_{2} \mathrm{~S}\right)$ is usually attributed to defined groups of bacteria and archaea $(1,2)$, and occurs primarily in anoxic environments.

62 During the process of dissimilatory sulfate reduction, sulfate acts as a terminal electron acceptor, and is converted to hydrogen sulfide. However, other pathways for $\mathrm{H}_{2} \mathrm{~S}$ production exist, namely assimilatory sulfate production, in which $\mathrm{H}_{2} \mathrm{~S}$ contributes to cell growth and increased biomass, and the conversion of sulfur-containing amino acids such as cysteine which can lead to production of pyruvate, ammonia, and $\mathrm{H}_{2} \mathrm{~S}$ (3). It is believed that assimilatory sulfate reduction contributes to growth but does not release $\mathrm{H}_{2} \mathrm{~S}$ from the cell, while dissimilatory sulfate reduction and cysteine degradation can contribute to growth and release ecologically relevant nitrogen and sulfur compounds into the ecosystem.

The sulfur cycle is composed of several assimilatory and dissimilatory pathways, which interact in complex ways through biotic and abiotic factors. Sulfur cycling in freshwater ecosystems can have significant ecological significance, especially in places where strong redox gradients exist (4). For example, in high arctic lakes, sulfur-compounds are suggested to serve as

75 biogeochemical hubs (5). Cysteine, a sulfur containing amino acid, has been proposed to be an

76 overlooked carbon source (6) and is an overlooked source of sulfur. Additionally, seston

77 (moving water that contains both living and nonliving organisms) contains organosulfur

78 containing lipids which settle into the sediments, and contributes to the sulfur pool in lakes such 79 as Lake Superior (7). 
81 In seasonally stratified lakes consisting of two layers of oxygenated warm water (epilimnion)

82 floating atop colder anoxic waters (hypolimnion), $\mathrm{H}_{2} \mathrm{~S}$ is often abundant in the hypolimnion (8,

83 9), due to the presence of anoxic sediment and an anoxic water column. However, an overlooked

84 player in the pool of available $\mathrm{H}_{2} \mathrm{~S}$ is the utilization of organosulfur compounds such as cysteine

85 by microbes. Cysteine is required for the production of proteins and is important for protein

86 structure. It is one of the two amino acids (methionine being the other) that contains a sulfur

87 group; however, the sulfhydryl group on cysteine is more reactive and can lead to the formation

88 of $\mathrm{H}_{2} \mathrm{~S}$. Like all amino acids, cysteine also contains an amine group that will form ammonia once

89 the molecule is degraded. As such, the degradation of cysteine by microbes leads to the

90 production of $\mathrm{H}_{2} \mathrm{~S} . \mathrm{H}_{2} \mathrm{~S}$ is ecologically relevant because it can be toxic to plants and animals.

91 During periods of anoxia, $\mathrm{H}_{2} \mathrm{~S}$ can accumulate to levels beyond the threshold for living

92 organisms, and can cause massive fish kills (10). Unlike other sources of $\mathrm{H}_{2} \mathrm{~S}$, cysteine

93 degradation could occur under oxic conditions, thereby expanding the environmental scope of

94 this sulfur pool. In addition, cysteine has been found to be able to be degraded under oxic

95 conditions in the laboratory, but little information exists on the natural prevalence of this process

96 in lakes. We expect that $\mathrm{H}_{2} \mathrm{~S}$ production in oxic environments (during the mixed water column

97 periods of the year, and throughout the stratified period in the mixed epilimnion) could result

98 from cysteine utilization by microbes.

In this study, we investigated the prevalence of organosulfur degradation in aquatic ecosystems,

101 using both laboratory and genomic evidence, to inform our understanding of oxic sulfur cycling

102 in freshwater lakes (Figure 1). First, we grew bacterial isolates enriched from Lake Mendota's

103 oxic epilimnion to quantify $\mathrm{H}_{2} \mathrm{~S}$ and ammonia production, which informs the potential for

104 organosulfur degradation in an oxygenated aquatic environment. We found 18 isolates producing

$105 \mathrm{H}_{2} \mathrm{~S}$ under oxygenic conditions. We selected three $\mathrm{H}_{2} \mathrm{~S}$-producing isolates for detailed

106 characterization using full-genome sequencing and chemical analyses to track cysteine and $\mathrm{H}_{2} \mathrm{~S}$

107 production over their growth: Stenotrophomonas maltophila, Stenotrophomonas S. bentonitica

108 (Gammaproteobacteria) and Chryseobacterium piscium (Bacteroidetes). In all three isolates,

109 cysteine decreased when $\mathrm{H}_{2} \mathrm{~S}$ increased over their exponential growth curve under oxic

110 conditions. Finally, we contextualized our laboratory results using a time-series of metagenomic

111 data from the same isolation source (Lake Mendota, WI), in order to inform the temporal 
112 importance of organosulfur degradation. We found that genes for cysteine utilization were

113 present and abundant throughout the time-series suggesting that the ability to degrade cysteine is 114 widely distributed in Lake Mendota.

\section{Results}

Isolates capable of $\mathrm{H}_{2} \mathrm{~S}$ production in oxic conditions

119 To answer the question of whether bacteria could produce $\mathrm{H}_{2} \mathrm{~S}$ in the presence of oxygen, we

120 grew pure culture isolates originally isolated from the water column of temperate eutrophic Lake

121 Mendota. We grew the isolates under control and treatment conditions (addition of cysteine), and

122 tracked $\mathrm{H}_{2} \mathrm{~S}$ production after 24 hours (Figure 2, Table S1). Using qualitative $\mathrm{H}_{2} \mathrm{~S}$

123 measurements, we found that 18 isolates produced $\mathrm{H}_{2} \mathrm{~S}$ when grown with cysteine. We

124 performed $16 \mathrm{~S}$ rRNA sequencing on the 29 isolates that produced $\mathrm{H}_{2} \mathrm{~S}$. Isolates that produced

125 both $\mathrm{H}_{2} \mathrm{~S}$ and ammonia were identified as Stenotrophomonas rhizophila, Stenotrophomona

126 maltophilia (Betaproteobacteria), Citrobacteria gillenii (Gammaproteobacteria) and

127 Chryseobacterium sp. (Bacteroidetes), whereas those producing $\mathrm{H}_{2} \mathrm{~S}$ but not ammonia were

128 identified as Pseudomonas arsenicoxydans, Pseudomonas mandelii, Pseudomonas migulae,

129 Pseudomonas thivervalensis, and Microbacterium flavescens.

\section{Detailed microbiological, chemical and genomic characterization in selected isolates}

133 Next, we selected 3 isolates (\#43, \#13 and \#66) representing distinct species that produced $\mathrm{H}_{2} \mathrm{~S}$ 134 for further characterization. These detailed characterizations include OD600-based growth rates, 135 and paired quantitative measurements of cysteine and $\mathrm{H}_{2} \mathrm{~S}$. The addition of cysteine resulted in 136 concommital production of $\mathrm{H}_{2} \mathrm{~S}$ over time (Figure 3A, Table S2). All organisms used L-cysteine 137 preferably to D-cysteine (Figure 3B, Table S3). 
Next, we also performed full-genome sequencing using combined short-read and long-read sequencing on these 3 isolates (Table 1). We performed full-genome sequencing because functional information such as gene content cannot be predicted reliably from 16S rRNA sequencing of the isolates alone. The full genome of Isolate 43 was assembled into a single circular genome, with estimated completeness of $100 \%$, and taxonomically assigned to Stenotrophomonas maltophila. Unlike the $16 \mathrm{~S}$ rRNA sequence which assigned it to $S$. rhizophila, the full-genome was actually closer to S. maltophila. The full genome of Isolate 13, 146 could be assembled into 2 long contigs, but also with completeness of $100 \%$ and taxonomically assigned to S. bentonitica. The Chryseobacter genome was assembled in one circular genome, and $100 \%$ complete, and assigned to Chryseobacterium piscium. Overall, the 16S rRNA

149 amplicon sequencing performed prior agreed with full-genome sequencing assignment in some cases, and in others, the whole-genome sequencing assignment allowed finer taxonomic resolution (such as in the case of Isolate 13), and overall provides more information about the genetic content of the genomes. The genomic content was then used to inform how or why $\mathrm{H}_{2} \mathrm{~S}$ might be produced in oxic environments, as shown in the laboratory experiment.

Using genome-level gene annotations of the 3 isolates, we identified the presence of genes involved in cysteine utilization. We identified genes involved in the degradation of cysteine to ammonia, pyruvate and $\mathrm{H}_{2} \mathrm{~S}$ : metC, malY, tnaA, cysM, cysK (these 5 start from L-cysteine), and dcyD (which uses D-cysteine as a starting substrate) (Table S4). However, we note that these genes may have other enzymatic activities, such as cysteine biosynthesis instead of degradation

Leveraging the full-genomic content of the 3 isolates (Table S6), we proposed a cellular map of these isolates (Figure 5A). All three isolates had genes related to central carbon metabolism: including the TCA cycle, glycolysis, gluconeogenesis, the pentose phosphate pathway and the

165 glyoxylate cycle. They could both generate fatty acids using fatty acid biosynthesis, and utilize 166 fatty acids through the beta-oxidation pathway. As expected, they had genes for the cysteine 167 metabolism, including cysteine biosynthesis pathways from homocysteine and serine, as well as 168 other amino acid utilization, such as methionine degradation pathway. 
In spite of these similarities, the three isolates also have distinguishing characteristics amongst them (Table S6, Figure 5B). For example, while all have genes for sulfur oxidation (sulfur

172 dioxygenase), genes for thiosulfate oxidation were present in the two Stenotrophomonas isolates

173 but not Chryseobacterium. Isolate \#66 (Chryseobacter piscium) contained a urease suggesting

174 the use of organic nitrogen in the form of urea but this was absent in the two Stenotrophomonas

175 isolates.

Finally, many more genes for sugar utilization were identified in the two Stenotrophomonas isolates in the comparison to Chryseobacterium.

Presence of cysteine-degrading organisms and genes in a five-year metagenomic

environmental time-series

To put these laboratory results and lab-grown organisms into a natural environment context, we leveraged previously published genomic time-series of Lake Mendota spanning 2008-2012 in the oxygenated epilimnion to search for the presence of cysteine degradation genes in metagenomic data.

First, we searched the time-series to see if organisms in our study were also present in the time series. To do this, we linked the $16 \mathrm{~S}$ rRNA sequences of the isolated organisms to the assembled metagenomes from the time series. We found that while the 16S rRNA sequences were also present in the time series (Table S7, S8, S9), and broadly distributed over time, these scaffolds were not part of binned genomes. Therefore, little information about these isolates would be gathered from metagenomic data only. As such, the full-genome sequencing we performed was particularly helpful in understanding the full genomic structure of the $\mathrm{H}_{2} \mathrm{~S}$-producing organisms.

Second, we searched for the 6 genes associated with cystine degradation and production of $\mathrm{H}_{2} \mathrm{~S}$

196 (Table S5) (in binned and unbinned scaffolds). In total, we searched over 22 million amino acid 197 sequences and identified 1882 hits to 5 genes, since no dcyD homologs (involved in the D198 cysteine to pyruvate, ammonia and hydrogen sulfide degradation pathway) were found (Figure

199 6, Table S10). cysK and malY were the genes with most corresponding matches at any time 
point, followed by metC and cysM. Only 2 scaffolds contained tnaA. Overall, after correcting for the genome size, there was no visible temporal trend of the genes, although genes were found throughout the 5-year time series.

Among these cysteine-degrading gene sequences, several were identified in binned MAGs distributed in genomes of Actinobacteria, Bacteroidetes, Chloroflexota, Cyanobacteria, Planctomycetes, Proteobacteria, and Verrucomicrobia, which are common freshwater bacteria, and broadly distributed in freshwater lakes. tnaA was only present in Bacteroidetes, but other genes were more broadly distributed.

\section{Discussion}

\section{Different types of $\mathrm{H}_{2} \mathrm{~S}$ production: the fate of cysteine and the origin of the $\mathrm{H}_{2} \mathrm{~S}$}

215 The $\mathrm{H}_{2} \mathrm{~S}$ producing isolates identified by us fell into two groups, ammonia-producing and 216 ammonia-consuming, when grown in media with cysteine. We hypothesize that those that 217 produced ammonia and $\mathrm{H}_{2} \mathrm{~S}$ in the presence of cysteine, but not under "controlled" conditions 218 were those that were potentially contributing to the $\mathrm{H}_{2} \mathrm{~S}$ pool. However, it is possible that the 219 isolates that consume ammonia also conduct the cysteine degradation pathway, but do not excrete ammonia from the cell. Instead, since ammonia is an important biological compound, it could be used by the organism instead of being released into the media and measured.

We do not believe that this occurs with $\mathrm{H}_{2} \mathrm{~S}$, and that most, if not all, of the isolates that produce $\mathrm{H}_{2} \mathrm{~S}$ in the presence of oxygen will excrete it from the cell. $\mathrm{H}_{2} \mathrm{~S}$ is toxic to organisms that undergo aerobic cellular respiration (11). There is evidence that some bacteria use $\mathrm{H}_{2} \mathrm{~S}$ as a 226 protective compound against antibiotics, but it also creates a large amount of stress on the cell 
internally as a source of sulfur, we did not identify any sulfide quinone oxidoreductases, flavocytochrome c dehydrogenases, or other genes for the oxidation or transformation of $\mathrm{H}_{2} \mathrm{~S}$. All 3 isolates were obligate aerobes based on laboratory assays.

Of the 20 amino acids, little is known about the cysteine in the environment. One of the difficulties in studying the fate of cysteine in oxic environmentsis that it can be oxidized into cystine (13), which E.coli has been shown to uptake (14). In a study of E.coli K-12 that lacked a cysteine transporter, cysteine was found to be able to enter the cell through transporters dedicated to other amino acids that worked best when no amino acids alternatives other than cysteine were present in the medium (15). It is likely that the majority of $\mathrm{H}_{2} \mathrm{~S}$ produced by the cell in the three isolates originates from cysteine given the demonstrated reduction in cystine concentrations when the isolates are grown with added cysteine (Figure 3), coupled with the

240 release of $\mathrm{H}_{2} \mathrm{~S}$ and production of ammonia.

\section{Genomic structure of the $\mathbf{H}_{2} \mathrm{~S}$-producing isolates}

243 Overall, the three isolates selected for whole genome sequencing revealed genes for cysteine

244 degradation into $\mathrm{H}_{2} \mathrm{~S}$. Based on laboratory studies, they were able to produce $\mathrm{H}_{2} \mathrm{~S}$ in the presence 245 of oxygen. All genomes were obligate aerobes, which brings interesting questions about the life 246 history of these organisms.

248 Little information is known about the ecology of Stenotrophomonas maltophilia,

249 Stenotrophomonas Bentonitica, and Chryseobacterium piscium in the natural environment. $S$.

250 bentonitica was originally characterized in bentonite formations, and was predicted to have high

251 tolerance to heavy metals (16), and has been observed in arctic seawater (17). C. piscium was

252 also isolated from a fish in the arctic ocean (18), but its ecological significance in the oceans 253 remains unknown. This previously described $C$. piscium strain LMG 23089 was not reported to

254 produce $\mathrm{H}_{2} \mathrm{~S}$ yet our genetic analyses suggest that it has the enzymatic machinery to degrade 255 cysteine. 
One possible explanation for this discrepancy is that LMG 23089 was previously grown on SIM medium to test $\mathrm{H}_{2} \mathrm{~S}$, which is lower resolution than the modern $\mathrm{H}_{2} \mathrm{~S}$ probes which measure $\mu \mathrm{M}$ concentrations, and because SIM medium uses thiosulfate as a sulfur source. As a side test on isolate \#66, $\mathrm{H}_{2} \mathrm{~S}$ was not produced when thiosulfate was provided, but $\mathrm{H}_{2} \mathrm{~S}$ was produced when cysteine was provided.

One particular finding of this study was that none of the 6 genes searched for cysteine degradation into $\mathrm{H}_{2} \mathrm{~S}$ and ammonia was common to all three isolates, despite all three isolates showing the same cysteine-decrease, ammonia-increase and $\mathrm{H}_{2} \mathrm{~S}$-increase over time. This could be explained by alternative, perhaps less straightforward pathways for $\mathrm{H}_{2} \mathrm{~S}$ production. One pathway is led by a gene named cystathionine gamma-lyase ("CTH" or "CSE"). In some bacteria and mammals, this enzyme is involved in $\mathrm{H}_{2} \mathrm{~S}$ production (19). A HMM search for this enzyme showed that it was present in Isolate \#13, 43 and \#66. While it was not initially included in the initial methods and study, this could hint to another commonality among oxic $\mathrm{H}_{2} \mathrm{~S}$ producing organisms. environment

Extrapolating these laboratory results to widespread distribution of organosulfur degradation in the natural environment necessitates several steps, namely because of the major gaps that exist concerning the sulfur cycle in freshwater lakes, and because bridging the gap between cultivation-based, omics-based (20), and field-based experiments is needed. Foremost, the identity, distribution, and availability of organosulfur compounds broadly across lakes globally is currently mostly unknown. Cysteine is notoriously difficult to measure, and many previous studies characterizing the amino acid composition of the water column only measure the sulfurcontaining organosulfur compound taurine $(21,22)$. in protein folding and function (23). As such, there is a difference in the fates of cysteine when it exists bound in cell walls, versus when cysteine is free in the water column and available for 
degradation by bacteria. While cysteine has been shown to contribute to the carbon pool and carbon flow in lakes (6), more quantitative field measurements are necessary to support whether cysteine also serves as a sulfur pool. Yet, other forms of organosulfur have important significance in aquatic environments. In marine environments for example DMSP (dimethylsulfoxonium propionate) is a critical component of the marine organosulfur cycle (24).

Additionally, current differences between computational gene homology searches versus in vivo enzymatic functions are challenging to assess for the genes responsible for the degradation of cysteine into pyruvate, ammonia and $\mathrm{H}_{2} \mathrm{~S}$. One reason is that the enzymatic activity of the gene has mostly been described in model organisms such as E. coli, and it has been shown that gene activity can be induced by genetic factors, or environmental factors such as metals (25). At least 6 genes have been proposed to have this enzymatic activity, yet, each gene may serve different functions in situ, and it is difficult to assert directionality of enzymatic function based on metagenomic or genomic analyses only. To this end, the isolated bacterial strains from this study, which are non-model organisms, and originate from the natural freshwater lake environment, may be used for further detailed biochemical, physiological, and microbiological studies. Further characterization of these bacterial isolates using gene-knockoutsand gene expression studies may inform the functional activity of these genes in nature.

\section{Implications of oxic $\mathrm{H}_{2} \mathrm{~S}$ production by microbes in freshwaters}

This study demonstrates that the production of $\mathrm{H}_{2} \mathrm{~S}$ by microbes in lake ecosystems occurs in the presence of oxygen, using evidence from pure culture bacterial isolates, and screening of longterm time series of metagenomic lake data. By combining lake-to-laboratory experiments, we

311 show that multiple bacterial strains spanning Gammaproteobacteria, Betaproteobacteria,

312 Actinobacteria and Bacteroidetes are all able to produce $\mathrm{H}_{2} \mathrm{~S}$ under oxic conditions, and at 313 temperatures that would be ecologically relevant for surface lake water during the summer.

314 Surface water temperatures in Lake Mendota can reach up to $27^{\circ} \mathrm{C}$, and the top few meters of 315 water surface are saturated in oxygen. Long-term ecological data shows such trends. Worldwide, 316 maximum lake surface temperature can range between 23 to $31^{\circ} \mathrm{C}$ (26) (Table S12). 
318 Unlike dissimilatory sulfate reduction, cysteine utilization by bacteria to generate ammonia,

319 pyruvate and $\mathrm{H}_{2} \mathrm{~S}$, is not dependent on sulfate as an initial reaction substrate. Increased sulfate

320 concentrations are shown to lead to higher sulfide reduction rates in shallow eutrophic

321 freshwater, the sulfur originating from algal decay for example (27). While Lake Mendota is a

322 low-iron and high sulfate lake (28), not all lakes have elevated sulfate levels, and therefore, $\mathrm{H}_{2} \mathrm{~S}$

323 production might previously not have been thought of as relevant to study. However, sulfur-

324 containing amino-acids can have many origins. In lakes, concentrations of amino acids (free and

325 combined) often reflect the input and outputs of the lake $(29,30)$. For example, amino acids

326 (although cysteine was not measured) contribute a detectable amount to the nitrogen cycle, and

327 are facilitated by bacterial activity (30).

There are several implications for aerobic $\mathrm{H}_{2} \mathrm{~S}$ production in oxygenated aquatic ecosystems. In the carbon cycle, once aerobic methanotrophs were identified as early as 1900's, further aerobic methanotrophs from various phyla of bacteria were found to be ubiquitous in aquatic ecosystems, and have had implications for the cycling of methane, a potent greenhouse gas that is $25 \mathrm{X}$ more potent than $\mathrm{CO}_{2}$. Likewise, the discovery of aerobic bacterial methanogenesis (31), contributes to resolving the "methane paradox", in which methane was often measured in oxygenic surface waters, yet the molecular paradigm explaining it previously was strictly known to occur in anoxic environments. In these two cases, the observation of the processes (methanogenesis and methane consumption) that were typically thought to occur in anoxic environments only, but in oxic environments now, are crucial for the understanding of the carbon (biogeochemical cycle). In a similar vein, much remains to be discovered about the sulfur cycle. In lakes, $\mathrm{H}_{2} \mathrm{~S}$ has typically been associated with anoxic environments, and from processes that are oxygen-

341 sensitive such as dissimilatory sulfate reduction. Here, we show hydrogen-sulfide production to

342 not only occur in oxic conditions but also by several guilds of bacteria, and in detectable

343 quantities.

345 Freshwater lakes which are dimictic can become stratified in temperature and oxygen during the 346 summer, and oxygen concentrations vary throughout the year. In the fall and spring, oxygen is 347 abundant, and cysteine degradation into $\mathrm{H}_{2} \mathrm{~S}$ could be a relevant process for the sulfur pool, and 
the fluxes of $\mathrm{H}_{2} \mathrm{~S}$ to the atmosphere could be significant since wind is prevalent. Under ice during the winter, where oxygen is plentiful, $\mathrm{H}_{2} \mathrm{~S}$ could be produced but could be consumed or oxidized, but gases would be trapped under ice. During summer, the anoxic hypolimnion and sediments are known sources of $\mathrm{H}_{2} \mathrm{~S}$ due to dissimilatory sulfate reduction, but density gradients would prevent $\mathrm{H}_{2} \mathrm{~S}$ from reaching the atmosphere. However, during the summer, the oxygenated mixed epilimnion could be sources of $\mathrm{H}_{2} \mathrm{~S}$ through organosulfur degradation. If we consider the importance of oxic hydrogen sulfide production, which could occur year-round, the pool of $\mathrm{H}_{2} \mathrm{~S}$ and the scope of sulfur transformations may be greater than anticipated, if we focus solely on the anoxic hypolimnion (Figure 7). Future work aiming to understand the broader distribution of sulfur-containing amino acids and other organosulfur compounds in freshwaters, their fates and transformations, as well as their contribution to $\mathrm{H}_{2} \mathrm{~S}$ production, will inform global sulfur biogeochemical cycling.

Methods

\section{Enrichment cultures of isolates from a temperate freshwater lake}

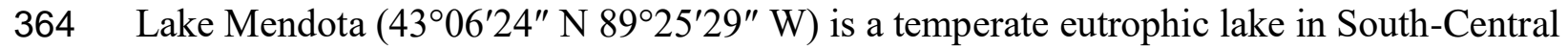

365 Wisconsin, in Madison, WI, USA. Lake Mendota is part of the Long-Term Ecological Research

366 Network North Temperate Lakes (NTL-LTER, https://lter.limnology.wisc.edu/about/lakes).

367 Lake Mendota encounters annual stratification and annual seasonal anoxia in the hypolimnion.

368 Lake water was collected on September 14, 2018 from an integrated water sample (0m to 12m)

369 from Lake Mendota at the Deep Hole location (4305'54", 89²4'28"), where the maximum

370 depth is $23.5 \mathrm{~m}$. The lake water was collected in pre-acid washed $2 \mathrm{~L}$ sampling bottles using a

371 flexible PVC tubing, and brought back on shore within hours for immediate processing. The

372 water samples were collected during stratification and the oxygenated epilimnion. Serial dilution

373 was performed and grown on PCB (plate count media broth) agar media, at room temperature

$374\left(\sim 21^{\circ} \mathrm{C}\right)$, in the lab. The PCB media was made of: $1 \mathrm{~L}$ water, $5 \mathrm{~g} / \mathrm{L}$ of yeast extract, $10 \mathrm{~g} / \mathrm{L}$ of 
tryptone and $2 \mathrm{~g} / \mathrm{L}$ of dextrose/D-glucose. If grown on solid media, $10 \mathrm{~g}$ of agar per $1 \mathrm{~L}$ media was added. Enrichment resulted in about 60 isolates.

\section{Screening for cysteine degradation into $\mathrm{H}_{2} \mathrm{~S}$ and ammonia}

379 Isolates were able to grow on PCB and R2A media. R2A media is a culture medium for bacteria that typically grow in water. It is less "nutrient rich" than PCB media, and therefore slightly closer to natural lake water. For the screening of the isolates for $\mathrm{H}_{2} \mathrm{~S}$ production, we grew them on R2A media. Each isolate had two treatments: grown in R2A media without cysteine for the control, and grown in R2A media with amended cysteine as the treatment. yeast extract, $0.3 \mathrm{~g}$ of $\mathrm{K}_{2} \mathrm{HPO}_{4}, 0.3 \mathrm{~g}$ of sodium pyruvate, $0.25 \mathrm{~g}$ of peptone, $0.25 \mathrm{~g}$ of beef extract, $0.024 \mathrm{~g}$ of $\mathrm{MgSO}_{4}$, and autoclave. To make the same media for plates, we added $15 \mathrm{~g}$ of agar before autoclaving. For controls, isolates were grown in the media without cysteine amendments. For "treatments", $2 \mathrm{mM}$ cysteine was added.

To assess the amount of cysteine degradation into $\mathrm{H}_{2} \mathrm{~S}$ and ammonia, we screened each 60 isolates on whether they produce $\mathrm{H}_{2} \mathrm{~S}$ and/or ammonia. To test $\mathrm{H}_{2} \mathrm{~S}$ production, we grew the strains individually in liquid media, and used lead acetate test strips (Fisher Scientific, USA) to qualitatively assess $\mathrm{H}_{2} \mathrm{~S}$ production. A darkening of the strip shows that $\mathrm{H}_{2} \mathrm{~S}$ was produced. To test ammonia concentrations after 24 hours, we measured samples at time zero, and 24 hours using Ammonia Salicylate Reagent Powder Pillows and Ammonia Cyanurate Reagent Powder Pillows (Hatch Reagents) and used spectrophotometry at the $655 \mathrm{~nm}$ wavelength.

\section{Identification of $\mathrm{H}_{2} \mathrm{~S}$ producing bacteria using $16 \mathrm{~S}$ rRNA sequencing}

400 Colony PCR and DNA extractions were conducted using the EtNa Crude DNA Extraction and 401 ExoSAP-ITTM PCR Product Cleanup protocols on the isolates that tested positive for producing $402 \mathrm{H}_{2} \mathrm{~S}(10)$. Full length $16 \mathrm{~S}$ rRNA products were generated for sequencing using universal 16S 403 rRNA primers (27f, 1492r). DNA concentration yields were measured using the qBit dsDNA HS 
assay kit (QuBit). DNA was sequenced at the University of Wisconsin Madison Biotechnology

405 Center (Madison, WI, USA) The program 4Peaks (32) was used to clean the base pairs by

406 quality-checking followed by homology search using BLASTn against the NCBI Genbank

407 database (accessed December 2019) (33) to identify the sequences.

408 Detailed characterization of 3 hydrogen-sulfide producing isolates

409 We selected 3 isolates that could aerobically produce $\mathrm{H}_{2} \mathrm{~S}$ for further detailed characterization.

410 We selected these isolates because some of the 18 isolates had identical 16S rRNA sequences,

411 therefore we chose isolates that had distinct 16S rRNA sequences for full-genome sequencing.

412 Additionally, using 16S rRNA sequencing of the isolate, one only was assigned to

413 Stenotrophomonas sp., and we believed that full-genome sequencing would enable us to get a

414 higher taxonomic confirmation and more complete information.

416 We performed DNA extraction using the PowerSoil Powerlyzer kit (Qiagen) without protocol

417 modifications, and sent the genomes for full genome sequencing at Microbial Genome

418 Sequencing Center (MIGS) (Pittsburg, PA) for combined short read illumina and long read

419 nanopore sequencing. The data was processed by MIGS to assemble the short-reads (Illumina

420 Next Seq 2000) and long-reads (Oxford Nanopore Technologies) into full-genomes. Quality

421 control and adapter trimming was performed with bcl2fastq (Illumina) and porechop

422 (https://github.com/rrwick/Porechop) for Illumina and ONT sequencing respectively. Hybrid

423 assembly with Illumina and ONT reads was performed with Unicycler (34). Genome annotation

424 of the 3 isolates was done with Prokka v.1.14.5(35), using the --rfam setting.

426 Genome completeness and contamination were estimated using CheckM v.1.1.3 (36)

427 lineage_wf. Taxonomic classification was conducted using GTDB-tk v.0.3.2 (37) with the 428 database release r95. The full-genome taxonomic classification agreed with the prior 16S rRNA

429 sequencing results, but we were further able to identify Isolate 43 as Stenotrophomonas

430 bentonitica. We ran METABOLIC-G v.4.0 (38) to identify genes associated with cysteine 431 degradation and other metabolic pathways. 
433 Growth measurements of the three isolates were measured using OD600 with a

434 spectrophotometer, with measurements every 1 hour. The isolates were grown in R2A broth

435 media, shaken in an incubator at $27^{\circ} \mathrm{C}$. Aliquots were collected over the growth range for

436 cysteine measurements. A $\mathrm{H}_{2} \mathrm{~S}$ microsensor (Unisense) was used to measure $\mathrm{H}_{2} \mathrm{~S}$ over time.

\section{Methods to measure Cysteine}

440 Cysteine concentrations were measured as cystine, as described in (39) (https://osf.io/9k8a6/).

441 One of the reasons for measuring cystine instead of cysteine is that in oxic environments,

442 cysteine is oxidized rapidly into cystine $(13,14)$. Additionally, unless LC-MS is used, cysteine

443 can be difficult to measure directly. Samples were diluted 5:4:1 Sample:DI $\mathrm{H}_{2} \mathrm{O}: \mathrm{DMSO}$ and left

444 at room temperature for at least 24 hours. Chromatographic analysis was performed on an

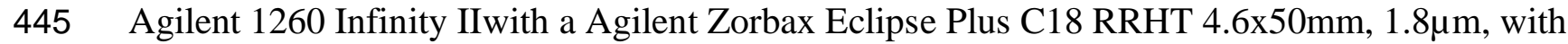

446 Guard column. Column temperature was maintained at $40^{\circ} \mathrm{C}$ using an Agilent $1260 \mathrm{TCC}$

447 (G1316A).

449 Gradient elution was performed using Mobile Phase A (MPA) consisting of 10mM $\mathrm{Na}_{2} \mathrm{HPO}_{4}$,

$45010 \mathrm{mM}$ Sodium Tetraborate Decahydrate, in $\mathrm{DI} \mathrm{H}_{2} \mathrm{O}$, adjusted to $\mathrm{pH} 8.2$ with $\mathrm{HCl}$, filtered to

$451 \quad 0.45 \mu \mathrm{m}$. Mobile Phase B (MPB) consisted of 45:45:10 Acetonitrile:Methanol:DI $\mathrm{H}_{2} \mathrm{O}$. Gradient

452 used for elution was as follows: 0 minutes 98\% MPA, 2\% MPB; 0.2 minutes 98\% MPA, 2\%

453 MPB; 6.67 minutes 46\% MPA, 54\% MPB; 6.77 minutes 0\% MPA, 100\% MPB; 7.3 minutes 0\%

454 MPA, 100\% MPB; 7.4 minutes 98\% MPA, 2\% MPB; 8 minutes 98\% MPA, 2\% MPB. Flow rate

455 was 2.0mL/min. Pump used was a Agilent Infinity Series G1311B Quat Pump. Pre-column

456 derivatization was performed using an Agilent 1260 ALS (G1329B) with an injector program.

457 Detection was performed using an Agilent 1260 Infinity II MWD (G7165A) at 338nm with

458 10nm bandwidth. Reference was 390nm with 20nm bandwidth.

459 Recovery was tested during method development. Recoveries of Cystine ranged from 87.2-

$460101.5 \%$, with an average of $92.1 \%$. 


\section{Methods to measure $\mathrm{H}_{2} \mathrm{~S}$ using a microsensor}

Aliquots of at least $1 \mathrm{~mL}$ were taken from cultures at desired times after inoculation. $\mathrm{H}_{2} \mathrm{~S}$ concentrations were measured by suspending the $\mathrm{H}_{2} \mathrm{~S}$ probe (Unisense) in the aliquot and leaving it in place until measurement stabilized. Measurements were manually edited to exclude data gathered while the probe was stabilizing in the sample.

\section{Generation of Metagenome-assembled genomes}

468 Sequencing of the Lake Mendota time series for 2008-2012 was previously done at the Joint 469 Genome Institute (40), containing 97 times points (and therefore 97 metagenomic datasets).

470 Metagenomics data was processed in-house. In summary, each metagenome was quality filtered 471 using fastp (41), and individually assembled using metaSPAdes. Each metagenome was mapped 472 to each individual assembly using BBMap v38.07 (42) version with 95\% sequence identity

473 cutoff. Differential coverage mapping to all samples was used to bin contigs into metagenome-

474 assembled genomes (MAGs) using Metabat2 v.2.12.1 (43). Bins were quality assessed with

475 CheckM v.1.1.2 (36), dereplicated with dRep v.2.4.2 (44), and classified with GTDB-tk v.0.3.2

476 (45). This resulted in a total of 116 MAGs from Lake Mendota (Table S13)

477 (https://osf.io/qkt9m/).

Searching for the presence of the three cultured isolates presence in the Lake Mendota time-series

481 To determine whether the isolates that were cultured in the laboratory were present in the natural 482 environment, we performed a homology search using Blastn v.2.6.0+ (33) of the 16S rRNA, 483 using an e-value threshold of 1e-6. 16S rRNA sequences were queried against a custom database 484 of the scaffolds in the assembly $(-\mathrm{db})$, with a further search against the binned scaffolds in the 485116 MAGs (-db). The comprehensive database containing all scaffolds of the assembly 486 comprised 16,599,321 scaffolds, whereas the final set of MAGs contained 28,395 scaffolds. 


\section{Searching for cysteine genes and isolates presence in time-series}

Genes for cysteine degradation were identified using HMMsearch v3.1b2 (46). HMMs were downloaded from KoFam (47), accessed May 2020). The KO numbers for the six cysteine degradation genes are: metC (K01760), cysK (K01738), cysM (K12339), malY (K14155), tnaA (K01667), and dcyD (K05396) (Table S4). Our HMM files are available in Supplementary File $\mathbf{1}$ but are the same published by KoFAM, with the modification of manual addition of the TC threshold. HMM-based homology searches were conducted on the 97 Lake Mendota metagenomes assemblies as described above.

\section{Data availability}

499 The $16 \mathrm{~S}$ rRNA sequences for the $29 \mathrm{H}_{2} \mathrm{~S}$ producing isolates, the full genome sequences

500 (nucleotides and amino acids) for isolates \#13, \#43 and \#66 are available on OSF:

501 https://osf.io/g25eq/ during the peer-review process. The sequences will be deposited in NCBI 502 prior to publication.

\section{Acknowledgements}

504 We are thankful to Anna Schmidt for collecting the original lake water from Lake Mendota in 505 2018, and to Adam Breister and Elizabeth Zanetakos who enriched the bacterial isolates during

506 summer 2018. We thank Trina McMahon's Lab and the Long-Term Ecological Research

507 Network, and the Center for Limnology for their field support and prior work on Lake Mendota.

508 We are thankful for the University of Wisconsin's Water Science and Engineering Laboratory for 509 the use of their HPLC instrumentation, and James Lazarcik for training and assistance with the 510 instruments.

511 This work was supported by the USDA National Institue of Food and Agriculture (NIFA) under 512 grant: Hatch project 1025641. Patricia Tran and Kristopher Kieft received the support from the 513 Anna Grant Birge Memorial Award from the Center for Limnology for support for the project in 514 2019. Patricia Tran is supported by the Natural Science and Engineering Research Council 515 (NSERC) of Canada Doctoral Fellowship. Samantha Bachand was supported by the National 
516 Science Foundation (NSF) Research Experience Undergraduate (REU) Award, and the

517 University of Wisconsin-Madison’ Holstrom Environmental Research Fellowship. Kristopher

518 Kieft was supported by a Wisconsin Distinguished Graduate Fellowship Award from the

519 University of Wisconsin-Madison, and a William H. Peterson Fellowship Award from the

520 Department of Bacteriology, University of Wisconsin-Madison.

521

\section{Contributions}

523

524 P.Q.T, S.C.B., J.C.H, K.K and K.A contributed to study design and conceptualization. P.Q.T, 525 S.C.B, J.C.H and K.K conducted experiments on the isolates. J.C.H performed the chemical 526 analyses of the isolates. P.Q.T, S.C.B and J.C.H conducted genomic analyses. P.Q.T, S.C.B and

527 E.A.M conducted metagenomic analyses. P.Q.T, S.C.B and J.C.H analyzed the data and

528 generated figures. P.Q.T, S.C.B, J.C.H and K.A drafted and edited the manuscript. All authors

529 provided feedback and suggestions. 


\section{References}

534 1. Foti M, Sorokin DY, Lomans B, Mussman M, Zacharova EE, Pimenov NV, Kuenen JG, Muyzer G. 2007. Diversity, Activity, and Abundance of Sulfate-Reducing Bacteria in Saline and Hypersaline Soda Lakes. Appl Environ Microbiol 73:2093-2100.

2. INGVORSEN K, BROCK T. 1982. ELECTRON FLOW VIA SULFATE REDUCTION AND METHANOGENESIS IN THE ANAEROBIC HYPOLIMNION OF LAKE MENDOTA. LIMNOLOGY AND OCEANOGRAPHY 27:559-564.

3. Tchong S-I, Xu H, White RH. 2005. L-cysteine desulfidase: an [4Fe-4S] enzyme isolated from Methanocaldococcus jannaschii that catalyzes the breakdown of L-cysteine into pyruvate, ammonia, and sulfide. Biochemistry 44:1659-1670.

4. Berg JS, Jézéquel D, Duverger A, Lamy D, Laberty-Robert C, Miot J. 2019. Microbial diversity involved in iron and cryptic sulfur cycling in the ferruginous, low-sulfate waters of Lake Pavin. PLOS ONE 14:e0212787.

5. Vigneron A, Cruaud P, Culley AI, Couture R-M, Lovejoy C, Vincent WF. 2021. Genomic evidence for sulfur intermediates as new biogeochemical hubs in a model aquatic microbial ecosystem. Microbiome 9:46.

6. Göbbels L, Poehlein A, Dumnitch A, Egelkamp R, Kröger C, Haerdter J, Hackl T, Feld A, Weller H, Daniel R, Streit WR, Schoelmerich MC. 2021. Cysteine: an overlooked energy and carbon source. Sci Rep 11:2139.

7. Petersen M, Schreiner KM, Hyde E, Sheik C, Katsev S. 2019. Characterization of Organic Sulfur in Lake Superior, and its Contribution to Sulfur Biogeochemical Cycling 2019:B11L2247.

8. Eckert W, Conrad R. 2007. Sulfide and Methane Evolution in the Hypolimnion of a Subtropical Lake: A Three-Year Study. Biogeochemistry 82:67-76.

9. Peterson BD, McDaniel EA, Schmidt AG, Lepak RF, Janssen SE, Tran PQ, Marick RA, Ogorek JM, DeWild JF, Krabbenhoft DP, McMahon KD. 2020. Mercury Methylation Genes Identified across Diverse Anaerobic Microbial Guilds in a Eutrophic SulfateEnriched Lake. Environ Sci Technol 54:15840-15851.

10. Reese BK, Anderson MA, Amrhein C. 2008. Hydrogen sulfide production and volatilization in a polymictic eutrophic saline lake, Salton Sea, California. Sci Total Environ 406:205218.

11. Kabil O, Banerjee R. 2010. Redox Biochemistry of Hydrogen Sulfide. J Biol Chem 285:21903-21907.

12. Pal VK, Bandyopadhyay P, Singh A. 2018. Hydrogen Sulfide in Physiology and Pathogenesis of Bacteria and Viruses. IUBMB Life 70:393-410. by molecular oxygen in aqueous solutions. Russian Chemical Bulletin 52:1135-1141. 
14. Korshunov S, Imlay KRC, Imlay JA. 2020. Cystine import is a valuable but risky process whose hazards Escherichia coli minimizes by inducing a cysteine exporter. Molecular Microbiology 113:22-39.

15. Zhou Y, Imlay JA. Escherichia coli K-12 Lacks a High-Affinity Assimilatory Cysteine Importer. mBio 11:e01073-20.

16. Chen M-X, Li H-Y, Ye X-S, He X-Y. Draft Genome Sequence of an Extracellular ProteaseProducing Bacterium, Stenotrophomonas bentonitica VV6, Isolated from Arctic Seawater. Genome Announcements 6:e01610-17.

17. Sánchez-Castro I, Bakkali M, Merroun ML. Draft Genome Sequence of Stenotrophomonas bentonitica BII-R7T, a Selenite-Reducing Bacterium Isolated from Spanish Bentonites. Genome Announcements 5:e00719-17.

18. de Beer H, Hugo CJ, Jooste PJ, Vancanneyt M, Coenye T, Vandamme P 2006. Chryseobacterium piscium sp. nov., isolated from fish of the South Atlantic Ocean off South Africa. International Journal of Systematic and Evolutionary Microbiology 56:1317-1322.

19. Sun Q, Collins R, Huang S, Holmberg-Schiavone L, Anand GS, Tan C-H, van-den-Berg S, Deng L-W, Moore PK, Karlberg T, Sivaraman J. 2009. Structural Basis for the Inhibition Mechanism of Human Cystathionine $\gamma$-Lyase, an Enzyme Responsible for the Production of H2S *. Journal of Biological Chemistry 284:3076-3085.

20. Hatzenpichler R, Krukenberg V, Spietz RL, Jay ZJ. 2020. Next-generation physiology approaches to study microbiome function at single cell level. Nat Rev Microbiol 18:241256.

21. Hubberten U, Lara RJ, Kattner G. 1994. Amino acid composition of seawater and dissolved humic substances in the Greenland Sea. Marine Chemistry 45:121-128.

22. Cindy, Lee. 2005. Amino Acid and Amine Biogeochemistry in Marine Particulate Material and Sediments.

23. Brosnan JT, Brosnan ME. 2006. The Sulfur-Containing Amino Acids: An Overview. The Journal of Nutrition 136:1636S-1640S.

24. Thume K, Gebser B, Chen L, Meyer N, Kieber DJ, Pohnert G. 2018. The metabolite dimethylsulfoxonium propionate extends the marine organosulfur cycle. Nature 563:412415.

25. Yamamoto K, Oshima T, Nonaka G, Ito H, Ishihama A. 2011. Induction of the Escherichia coli cysK gene by genetic and environmental factors. FEMS Microbiol Lett 323:88-95.

26. Sharma S, Gray DK, Read JS, O’Reilly CM, Schneider P, Qudrat A, Gries C, Stefanoff S, Hampton SE, Hook S, Lenters JD, Livingstone DM, McIntyre PB, Adrian R, Allan MG, Anneville O, Arvola L, Austin J, Bailey J, Baron JS, Brookes J, Chen Y, Daly R, Dokulil M, Dong B, Ewing K, de Eyto E, Hamilton D, Havens K, Haydon S, Hetzenauer H, Heneberry J, Hetherington AL, Higgins SN, Hixson E, Izmest'eva LR, Jones BM, Kangur K, Kasprzak P, Köster O, Kraemer BM, Kumagai M, Kuusisto E, Leshkevich G, May L, MacIntyre S, Müller-Navarra D, Naumenko M, Noges P, Noges T, Niederhauser P, North RP, Paterson AM, Plisnier P-D, Rigosi A, Rimmer A, Rogora M, Rudstam L, Rusak JA, Salmaso N, 

Teubner K, Verburg P, Voutilainen A, Watkinson A, Weyhenmeyer GA, Williamson CE, Woo KH. 2015. A global database of lake surface temperatures collected by in situ and satellite methods from 1985-2009. Sci Data 2:150008.

27. Chen M, Li X-H, He Y-H, Song N, Cai H-Y, Wang C, Li Y-T, Chu H-Y, Krumholz LR, Jiang H-L. 2016. Increasing sulfate concentrations result in higher sulfide production and phosphorous mobilization in a shallow eutrophic freshwater lake. Water Res 96:94-104.

28. Brock TD, Brock TD, Brock WA. 1985. A Eutrophic Lake: Lake Mendota, Wisconsin. Springer-Verlag.

29. Jørgensen NOG. 1987. Free amino acids in lakes: Concentrations and assimilation rates in relation to phytoplankton and bacterial production1. Limnology and Oceanography 32:97111.

30. Gardner W, Lee G. 1975. The role of amino acids in the nitrogen cycle of Lake Mendota. Limnology and Oceanography - LIMNOL OCEANOGR 20:379-388.

31. Wang Q, Alowaifeer A, Kerner P, Balasubramanian N, Patterson A, Christian W, Tarver A, Dore J, Hatzenpichler R, Bothner B, Mcdermott T. 2021. Aerobic bacterial methane synthesis. Proceedings of the National Academy of Sciences 118:e2019229118.

32. Nucleobytes. 4Peaks: For peaks, four peaks. The DNA sequence trace viewer for OS X.

33. Camacho C, Coulouris G, Avagyan V, Ma N, Papadopoulos J, Bealer K, Madden TL. 2009. BLAST+: architecture and applications. BMC Bioinformatics 10:421.

34. Wick RR, Judd LM, Gorrie CL, Holt KE. 2017. Unicycler: Resolving bacterial genome assemblies from short and long sequencing reads. PLOS Computational Biology 13:e1005595.

35. Seemann T. 2014. Prokka: rapid prokaryotic genome annotation. Bioinformatics 30:20682069.

36. Parks DH, Imelfort M, Skennerton CT, Hugenholtz P, Tyson GW. 2015. CheckM: assessing the quality of microbial genomes recovered from isolates, single cells, and metagenomes. Genome research 25:1043-55.

37. Parks DH, Chuvochina M, Waite DW, Rinke C, Skarshewski A, Chaumeil P-A, Hugenholtz P. 2018. A standardized bacterial taxonomy based on genome phylogeny substantially revises the tree of life. Nature Biotechnology 36:996-1004.

38. Zhou Z, Tran P, Liu Y, Kieft K, Anantharaman K. 2019. METABOLIC: A scalable highthroughput metabolic and biogeochemical functional trait profiler based on microbial genomes. bioRxiv 761643.

39. Hotvedt, Jacob C, Anantharaman, Karthik. 2021. Rapid and cheap quantification of Cysteine viaoxidationto Cystine by DMSO and Ortho-phthalaldehyde pre-column derivatization.

40. Bendall ML, Stevens SL, Chan L-K, Malfatti S, Schwientek P, Tremblay J, Schackwitz W, Martin J, Pati A, Bushnell B, Froula J, Kang D, Tringe SG, Bertilsson S, Moran MA, Shade 
A, Newton RJ, McMahon KD, Malmstrom RR. 2016. Genome-wide selective sweeps and gene-specific sweeps in natural bacterial populations. The ISME Journal 10:1589-1601.

41. Chen S, Zhou Y, Chen Y, Gu J. 2018. fastp: an ultra-fast all-in-one FASTQ preprocessor. Bioinformatics 34:i884-i890.

42. Bushnell B. 2014. BBMap: A Fast, Accurate, Splice-Aware Aligner. LBNL-7065E. Lawrence Berkeley National Lab. (LBNL), Berkeley, CA (United States). adaptive binning algorithm for robust and efficient genome reconstruction from metagenome assemblies. PeerJ 7:e7359.

44. Olm MR, Brown CT, Brooks B, Banfield JF. 2017. dRep: a tool for fast and accurate genomic comparisons that enables improved genome recovery from metagenomes through de-replication. The ISME Journal 1-5. genomes with the Genome Taxonomy Database. Bioinformatics 36:1925-1927.

664 47. Aramaki T, Blanc-Mathieu R, Endo H, Ohkubo K, Kanehisa M, Goto S, Ogata H. 2019. KofamKOALA: KEGG ortholog assignment based on profile HMM and adaptive score threshold. bioRxiv https://doi.org/10.1101/602110. 


\section{List of Main and Supplementary Figures \& Tables}

670 List of figures

671 Figure 1. Overview of methods of our study.

672 Figure 2. $\mathrm{H}_{2} \mathrm{~S}$ and ammonia production screening of the isolates

673 Figure 3. $\mathrm{H}_{2} \mathrm{~S}$ utilization, L-cysteine and D-cysteine utilization by the 3 isolates over time.

674 Figure 4. Diagram showing presence and absence of cysteine degradation genes in the 3 isolates.

675 Figure 5. Cellular diagram of genes and pathways common to all three isolates.

676 Figure 6. Cysteine utilization/degradation genes in the Lake Mendota Time Series (LMTS)

677 assemblies, and in the MAGs from that assembly.

678 Figure 7. Conceptual model of the potential importance of the cysteine degradation in a

679 freshwater lake water column, with respect to oxygen levels and seasonality.

\section{List of Tables}

682 Table 1. Description of the 3 isolates (genome size, taxonomy, etc.)

\section{List of Supplementary Tables}

685 Table S1. Description of all initial isolates used in screening

686 Table S2. Quantitative measurement of $\mathrm{H}_{2} \mathrm{~S}$ over time in the 3 isolates

687 Table S3. Quantitative measurement of cystine over time in the 3 isolates.

688 Table S4. Description of the 6 genes involved in the degradation of L-cysteine or D-cysteine into 689 pyruvate, ammonia and hydrogen sulfide

690 Table S5. Detailed list of all potential enzymatic activities of genes in the cysteine degradation 691 and biosynthesis pathways.

692 Table S6. METABOLIC table: Full genomic content of the 3 isolates

693 Table S7. HMMsearch table output of $16 \mathrm{~S}$ rRNA amplicons of the 28 isolates that produce $\mathrm{H} 2 \mathrm{~S}$

694 from Figure 1 against the Lake Mendota Time Series assembly.

695 Table S8. HMMsearch table output of 16S rRNA amplicons of the 28 isolates that produce H2S

696 from Figure 1 against the metagenome-assembled-genomes from the LMTS.

697 Table S9. HMMsearch table output of 16S rRNA amplicons of the 28 isolates that produce H2S

698 from Figure 1 against the SSU (16S small ribosomal subunit) of the metagenome-assembled-

699 genomes from the LMTS. 
700 Table S10. Cysteine hits the Assembly.

701 Table S11. Cysteine hits to MAGS

702 Table S12. MAG characteristics binned from LMTS.

703 Table S13. Global minimum and maximum lake surface temperatures (ref. Sharma et al., 2015)

704

705 List of Supplementary Files

706 File S1. HMM profiles.zip 
708 Tables

709 Table 1. Genome characteristics of 3 selected isolates that produce $\mathrm{H} 2 \mathrm{~S}$ in the presence of

710 oxygen and cysteine

711

\begin{tabular}{|c|c|c|c|c|c|c|}
\hline Name & $\begin{array}{l}\text { Genome } \\
\text { Size (bp) }\end{array}$ & $\begin{array}{l}\text { Comple } \\
\text { teness }^{1}\end{array}$ & $\begin{array}{l}\text { GC } \\
\text { content }\end{array}$ & Taxonomy ${ }^{2}$ & $\begin{array}{l}\text { NCBI Project } \\
\text { ID }\end{array}$ & Number of contigs \\
\hline $\begin{array}{l}\text { Isolate 13-LM- } \\
\text { B-02-08 }\end{array}$ & $4,188,104$ & $100 \%$ & $66.8 \%$ & $\begin{array}{l}\text { d__Bacteria;p__Proteobacte } \\
\text { ria;c__Gammaproteobacteri } \\
\text { a;o__Xanthomonadales;f__ } \\
\text { Xanthomonadaceae;g__Sten } \\
\text { otrophomonas;s_Stenotro } \\
\text { p } \\
\text { homonas maltophilia_o }\end{array}$ & TBD & 1 \\
\hline $\begin{array}{l}\text { Isolate43-LM- } \\
\text { B-01-03 }\end{array}$ & $4,325,715$ & $100 \%$ & $66.5 \%$ & $\begin{array}{l}\text { d__Bacteria;p__Proteobacte } \\
\text { ria;c__Gammaproteobacteri } \\
\text { a;o__Xanthomonadales;f__ } \\
\text { Xanthomonadaceae;g__Sten } \\
\text { otrophomonas;s_Stenotro } \\
\text { p } \\
\text { homonas bentonitica }\end{array}$ & TBD & 2 \\
\hline LM_BA_5.2 & $1,375,102$ & $100 \%$ & $33.7 \%$ & $\begin{array}{l}\text { d__Bacteria;p__Bacteroidot } \\
\text { a;c__Bacteroidia;o__Flavob } \\
\text { acteriales;f__Weeksellaceae } \\
\text {;g__Chryseobacterium;s__ } \\
\text { Chryseobacterium } \\
\text { piscium }\end{array}$ & TBD & 7 \\
\hline
\end{tabular}

${ }^{1}$ Using CheckM (See Methods) $\quad{ }^{2}$ Using GTDB-tk (See Methods) 


\section{Figures}

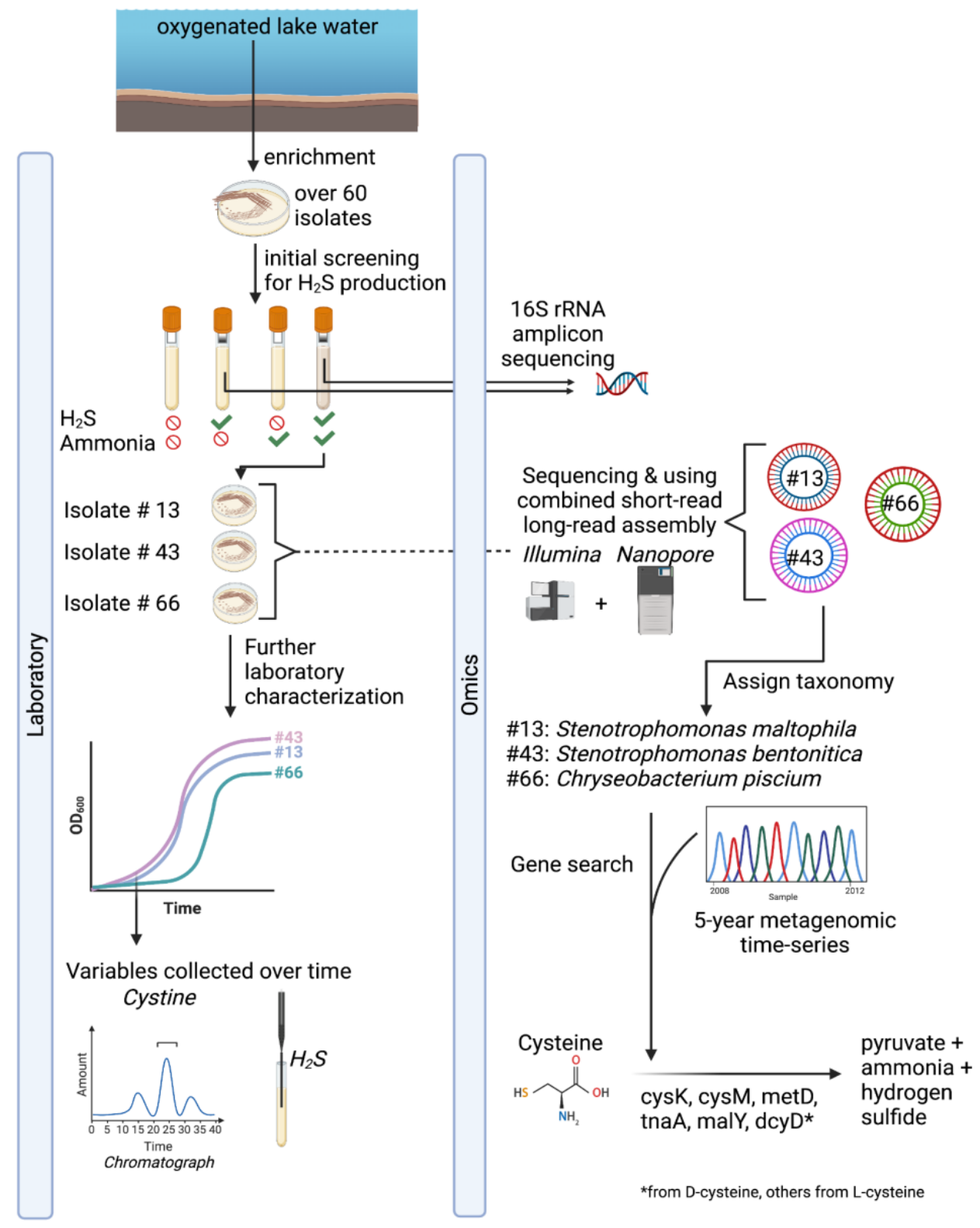

Figure 1. Methods overview of our study. Isolates were enriched from oxygenated lake water. Isolates were screened for $\mathrm{H}_{2} \mathrm{~S}$ and ammonia production, and those that produced $\mathrm{H}_{2} \mathrm{~S}$ were selected for $16 \mathrm{~S}$ rRNA sequencing. Then based on the results, three isolates were selected for whole-genome sequencing using a combination of short and long-reads. Genome characterization of functional potential and taxonomic classification was conducted on the isolates. Genes involved in cysteine degradation were searched in the isolates, and a five-year metagenomic time series of Lake Mendota (2008-2012). 


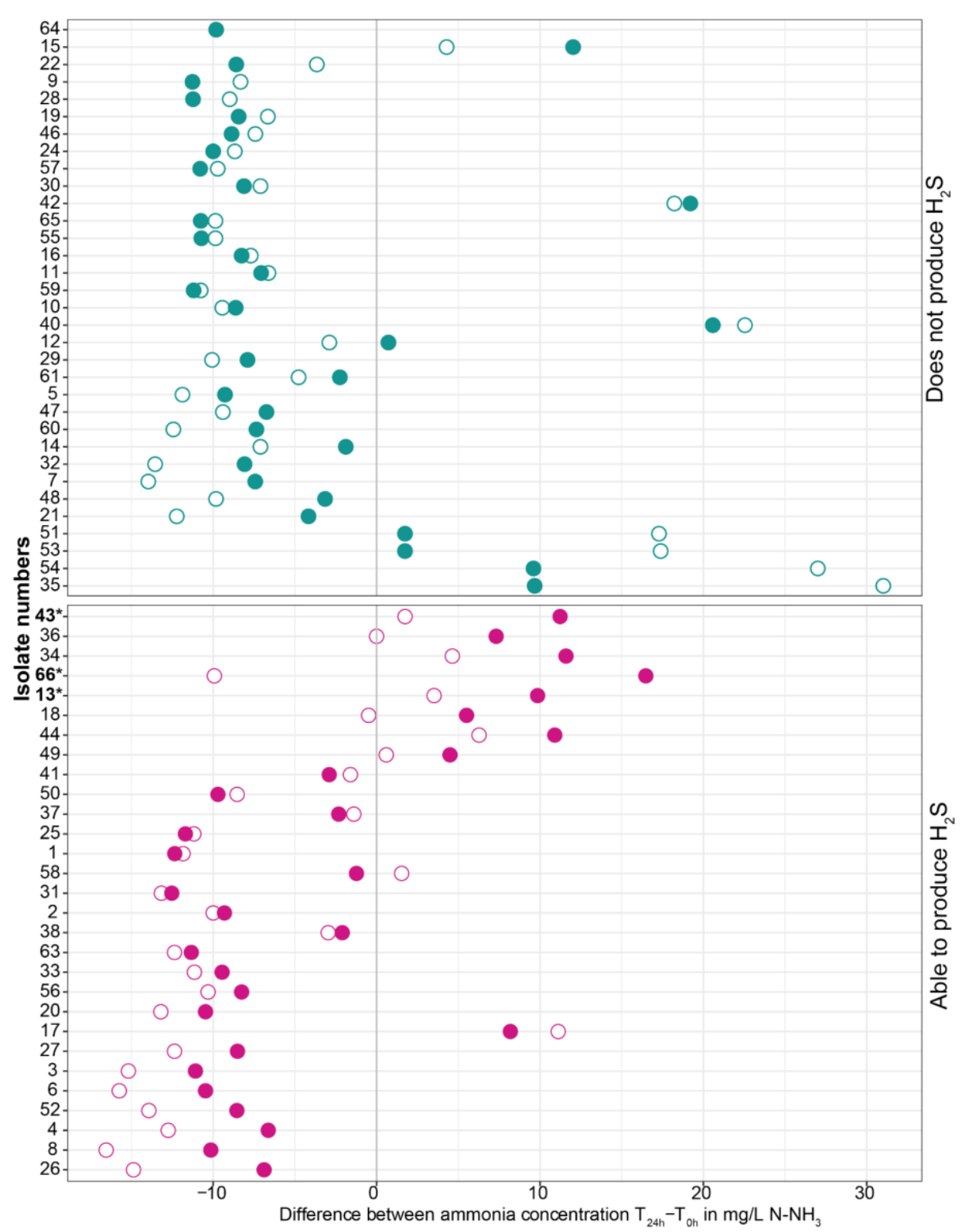

726 from a freshwater lake water column. Filled circles are isolates when grown with cysteine, and open circles are isolates when grown without cysteine. The vertical line represents values

728 corrected for the control (natural ammonia production/consumption in the negative control). All 729 points to the right of the vertical lines indicate a production of ammonia, and all points to the left 730 of the vertical lines refer to those that consumed ammonia after 24 hours. The isolates \#43, \#13 731 and \#66 were selected for further analysis. 


\section{A}

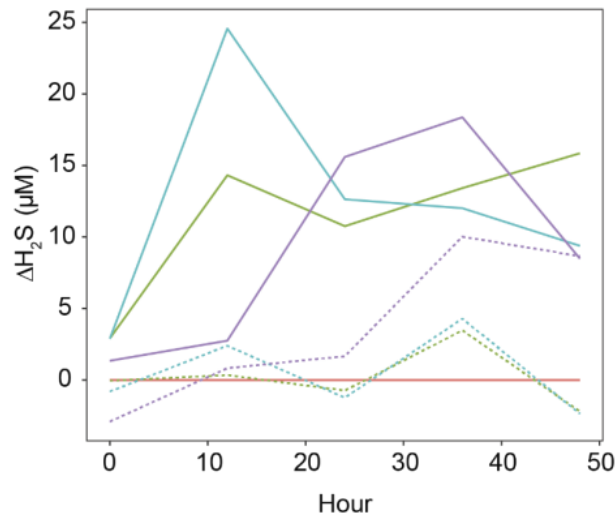

B

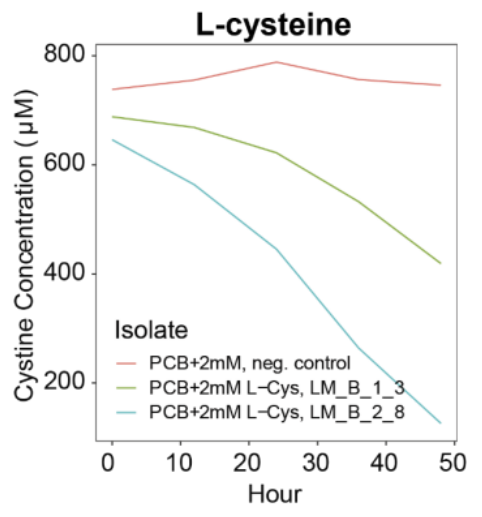

C

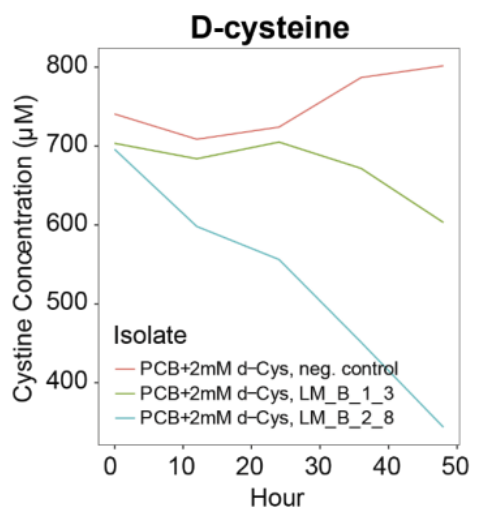

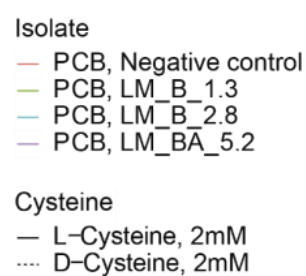

.... D-Cysteine, $2 \mathrm{mM}$

Figure 3. Further characterization of the three isolates and demonstration of cysteine

735 degradation and $\mathrm{H}_{2} \mathrm{~S}$ production. A. Higher amounts of $\mathrm{H}_{2} \mathrm{~S}$ was produced by the three isolates

736 over 50 hours compared to negative controls. B, C, D. Identification of different forms of

737 cysteine that can be degraded. L-cysteine decreased in all isolates compared to the control (B,

738 D). D-cysteine also decreased over time in all except the negative control, however, the net

739 amount decreased was less compared to L-cysteine. Cysteine concentrations were measured as

740 Cystine as described in the methods. Because Isolate \#13 and \#43 were assessed in another

741 experiment than \#66, but using the exact same instruments and methods, plots are separated by

742 HPLC runs. Due to large sample volume it was not possible to test all isolates and conditions in

743 one HPLC run. 


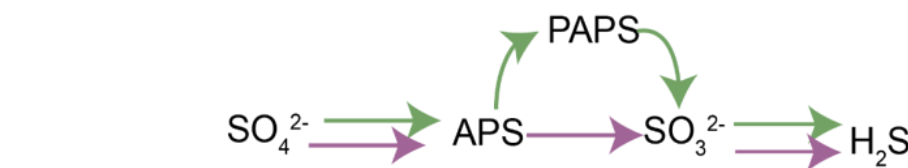

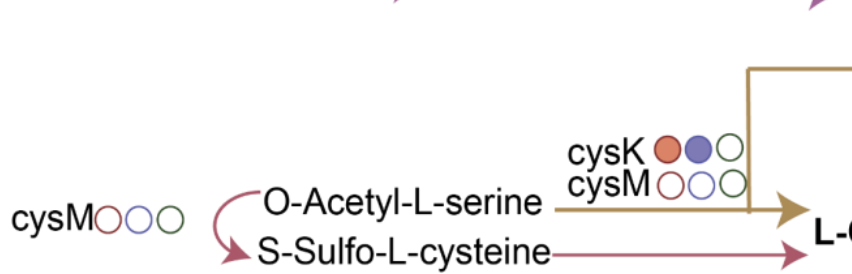

Arrows legend

Assimilatory Sulfate Reduction

Dissimilatory Sulfate Reduction

Organo-sulfur Degradation

Reverse Transsulfuration

Cysteine Biosynthesis (serine metabolism)

Cysteine Biosynthesis

\section{Circles legend \\ Presence Absence}

Isolate \#43 LM.B.01.03

(S. maltophila)

Isolate \#13 LM.B.02.08

(S. bentonitica)

Isolate \#66 LM.BA.05.02 $00 \mid$ Bacteroidetes
(C. piscium)

Gammaproteobacteria

\section{cysK $\mathrm{OOO}$}

cysMOO०

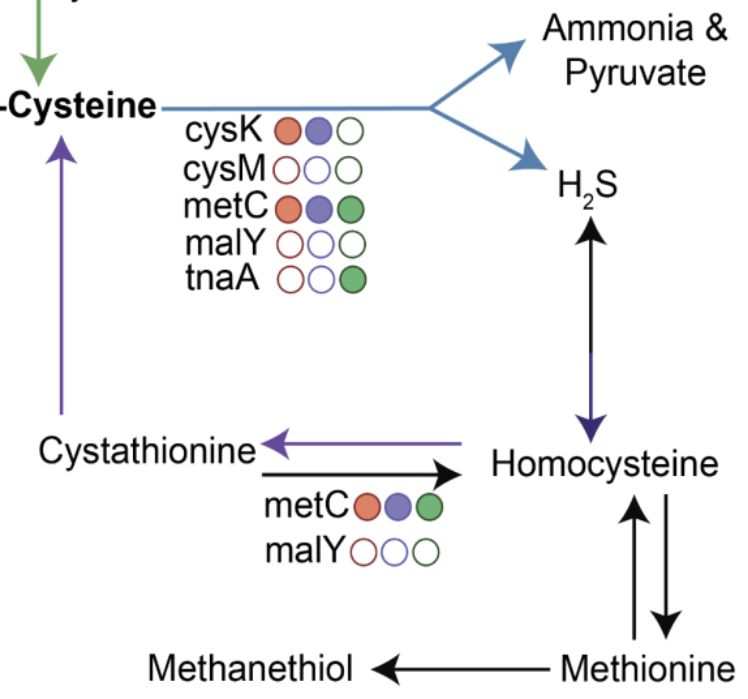

\section{Figure 4. Diagram showing pathways for sulfur and organosulfur metabolism. Several}

747 pathways for hydrogen sulfide and cysteine production exist in microorganisms. The

748 presence/absence of key genes (cysK, cysM, malY, cysM, metC, tnaA, sseA, aspB, and dcyD

749 along the blue arrow) in the three isolate's genomes are shown by filled (present) circles, and

750 clear (not present) circles. 


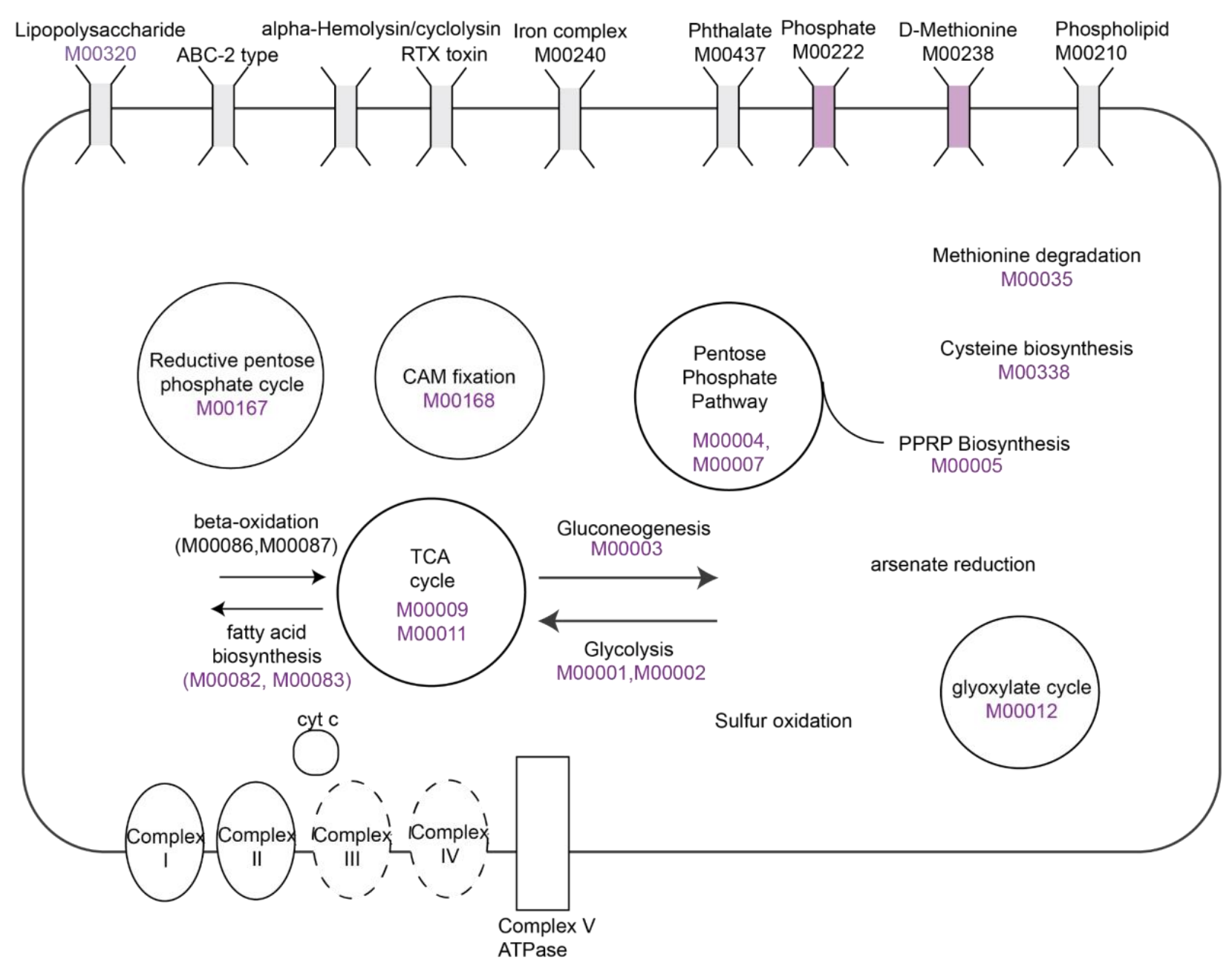

755 Figure 5A. Cellular map showing the pathways, genes, cycles and transporters which were

756 common to all three isolates. A complete list is found in Table S6. The KEGG module

757 identifiers are listed in purple whenever relevant. 


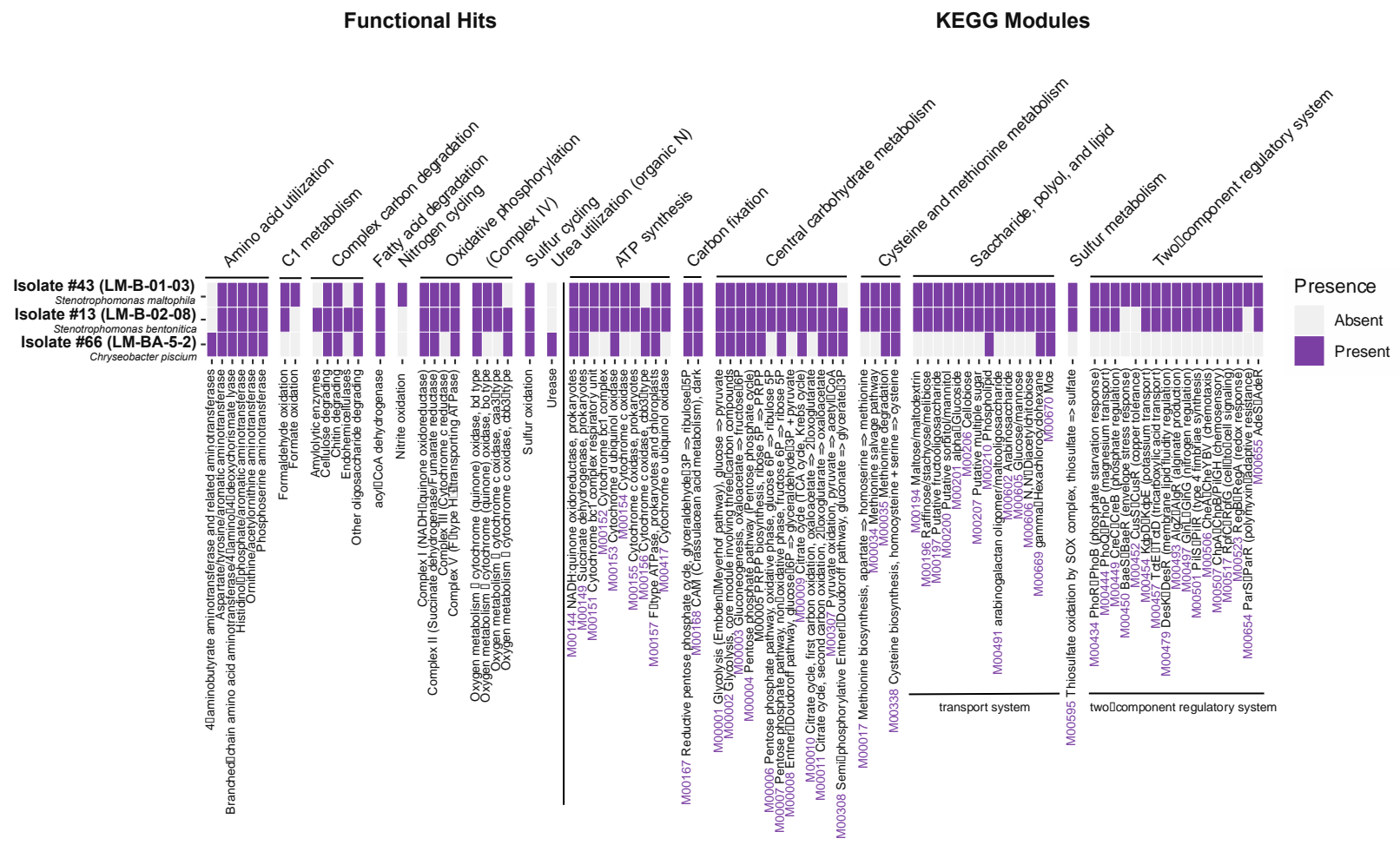


A

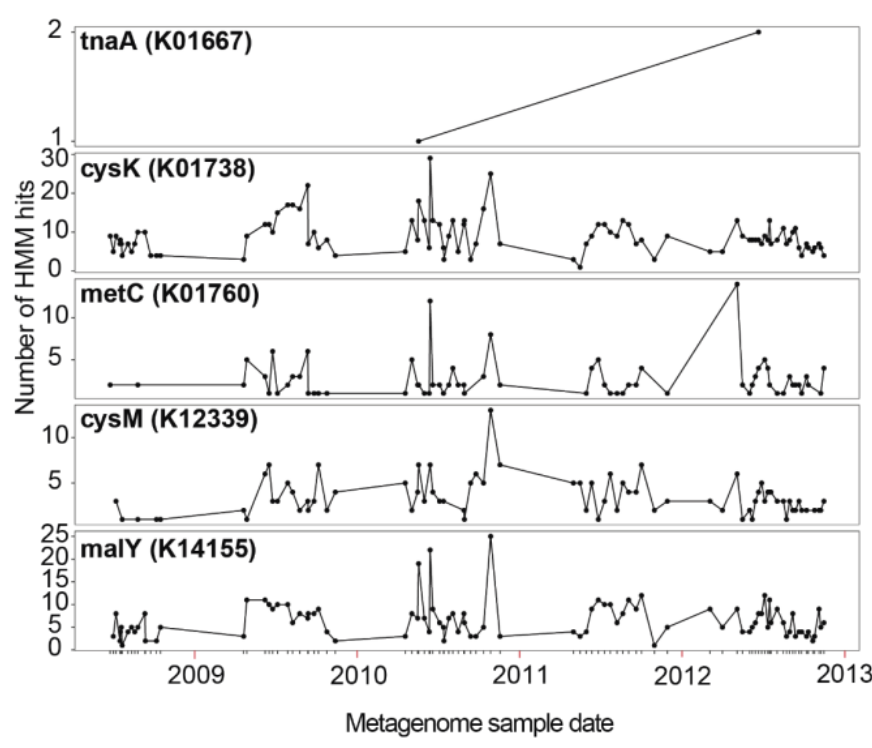

B

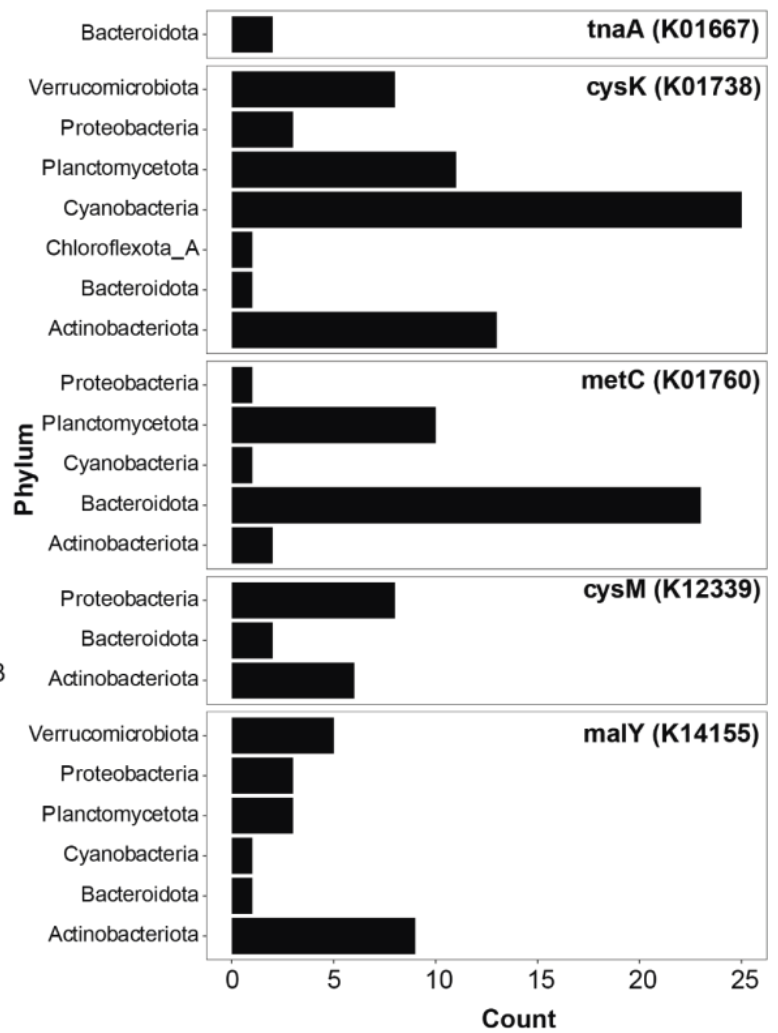

Figure 6. A. Number of amino acid coding sequences matching one of the cysteine genes searched ( 5 genes) which may have the enzymatic activity of degrading cysteine into

767 ammonia, pyruvate and hydrogen sulfide. We also searched for dcyD (6th gene) but did not

768 identify it in any sample. B. Presence of these 5 genes in the binned metagenome-assembled

769 metagenomes of the same time series. 


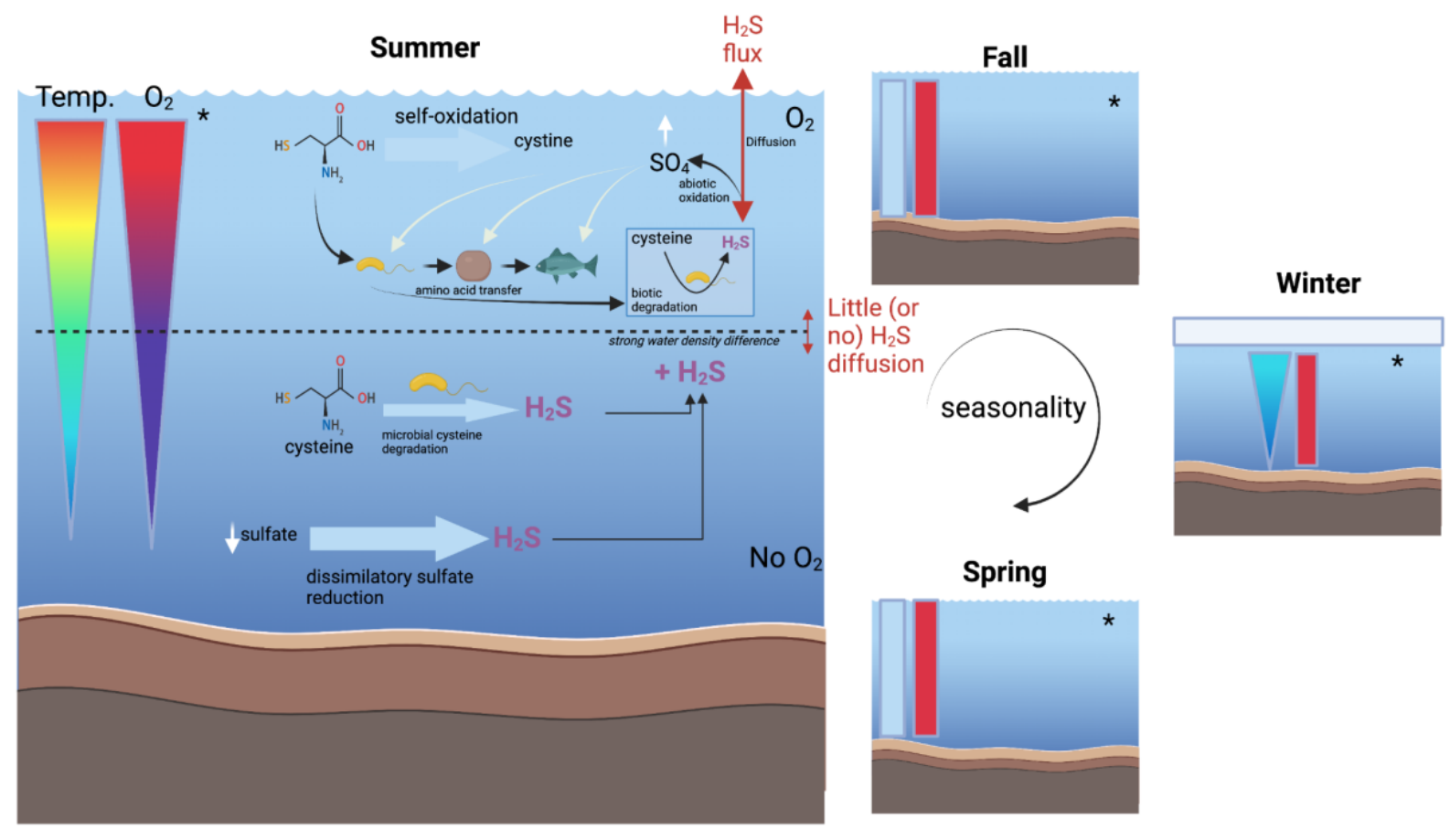

772 Figure 7. Conceptual figure showing the potential relevance of cysteine degradation in a 773 freshwater lake environment, with respect to oxygen availability and seasonality.

774 Oxygenated seasons and part of the lake water columns are shown with an asterix. Significant 775 research gaps include cysteine concentrations in the natural environment over time, $\mathrm{H}_{2} \mathrm{~S}$ fluxes

776 across different layers in the lake water column, and contribution of different $\mathrm{H}_{2} \mathrm{~S}$ sources in the 777 hypolimnion. 